glycine betaine or choline. If cells grown on glucose $/ \mathrm{NH}_{4}{ }^{+}$were transferred to a medium containing carnitine, an induction of the enzyme begins (Fig. I). This induction is completely inhibited by chloramphenicol. In the simultaneous presence of glucose $/ \mathrm{NH}_{4}{ }^{+}$and carnitine, the enzyme is only induced if glucose is completely metabolized. Structural analogues of carnitine (D-carnitine, L-carnitine amide, DL4-dimethylethylammonio-3-hydroxybutyrate, DL-4-dimethylamino-3-hydroxybutyrate, choline, and glycine betaine) are not inducers of carnitine dehydrogenase.

The present data support our concept that the first step of the assimilation of carnitine in $P s$. aeruginosa is the oxidation of $\mathrm{C}-3$. Carnitine induces the enzyme ( $\mathrm{NAD}^{+}$-linked and stereospecific for L-carnitine) called carnitine dehydrogenase (systematic name: L-carnitine: $\mathrm{NAD}^{+}$-oxidoreductase), which is probably a $\mathrm{SH}$ enzyme. The synthesis of carnitine dehydrogenase is repressed by glucose. If it is possible to increase specific activity by purification of the enzyme, carnitine dehydrogenase should be ahle to serve for the determination of L-carnitine by a simple optical test.

Institute of Physiological Chemistry, Karl Marx University,

HaRaLd AURICH

Leipzig (D.D.R.)

HANS-PETER KLEBER WULF-DiETER SCHÖPP

I H. Aurich and I. Lorenz, Acta Biol. Med. Ger., 3 (I959) 272.

2 H. Aurich and H.-P. Kleber, Acta Biol. Med. Ger., I 7 (I966) 694.

3 E. Strack, H. Aurich and E. Grüner, $Z$. Allgem. Mikrobiol., 4 (1964) I54.

4 T. Unemoto, M. Hayashi, K. Miyaki and M. Hayashi, Biochim. Biophys. Acta, I2I (I966) 220.

5 G. Lindstedt and S. Lindstedt, in G. Wolf, Recent Research on Carnitine, Mass. Inst. Technol. Press, I 965.

6 H.-P. Kleber, W.-D. Schöpp, H. Sorger, H. Tauchert and H. Aurich, in the press.

7 J. R. Stern, M. J. Coon and A. Del Campillo, J. Biol. Chem, 22 I (1956) I.

8 E. Grüner and E. Strack, Z. Physiol. Chem., 338 (1964) 84 .

Received March 3Ist, I967

Biochim. Biophys. Acta, 139 (1967) 505-507

BBA $6325 \mathrm{I}$

\title{
Reactions of the lactate dehydrogenase $X$-band in human sperm with homologous and heterologous antisera
}

The electrophoretic separation of homogenates of mature testes from a number of animal species results in the detection of one or more lactate dehydrogenase isozymes (L-lactate:NAD oxidoreductase, EC I.I.I.27) which are not found in other tissues ${ }^{1,2}$. These isozymes, which have been referred to as the $\mathrm{X}$-bands ${ }^{1}$, have been shown to comprise 80 to $100 \%$ of the total lactate dehydrogenase activity in sperm, and it appears that sperm may be their source in testes ${ }^{1,3}$. It has been suggested, on the basis of dissociation and hybridization experiments performed with human and rabbit testes, that the $\mathrm{X}$-band consists of subunits which are different from the $\mathrm{A}$ or B subunits of isozymes 5 or $\mathrm{I}$, and that its synthesis is controlled by a third gene ${ }^{4}$, 
(in addition to the other two which are believed to control the synthesis of A or B subunits). Hybridization experiments and the types of distribution patterns obtained with pigeon testes are also consistent with this hypothesis ${ }^{\mathbf{5}}$.

Various characteristics of the enzymatic activity of the X-band have been compared with those of the other isozymes, and it has generally been found that some of them are intermediate between those of isozymes I and 5, while others are distinct ${ }^{1-3,6,7}$. To the best of our knowledge, however, investigations of the structural or immunochemical properties of the X-band have not been published. Since immunochemical procedures are of value in distinguishing structural differences between various isozymes ${ }^{8-10}$, the $\mathrm{X}$-band in human sperm has been studied by this method. The results, described below, indicate that the structure of this isozyme cannot be accounted for on the basis of a tetramer composed of normal $\mathrm{A}$ and $\mathrm{B}$ subunits.

Human sperm were obtained from semen ejaculates by centrifugation, decantation, washing with normal saline, centrifugation, and decantation. Since it has been shown that washing can result in a loss of enzymatic activity ${ }^{1}$, the time the sperm were in contact with the saline was kept as short as possible. The sperm were then suspended in distilled water and sonicated. Human heart and liver tissues were obtained from autopsies. Each was homogenized in distilled water ( $\mathrm{I} \mathrm{ml} \mathrm{per} \mathrm{g}$ of tissue). Total lactate dehydrogenase activity was determined by the procedure of CAPPs $e t$ al. ${ }^{11}$. Isozymes I and 5 were isolated from heart and liver homogenates, respectively, by preparative electrophoresis, as previously described ${ }^{12}$. The only modification was the substitution of agarose for agar. Each fraction was free of detectable impurities.

Antisera were prepared by various subcutaneous injections into rabbits of $\mathrm{I} \mathrm{ml}$ of an emulsion, which consisted of $0.5 \mathrm{ml}$ of complete Freund's adjuvant and $0.5 \mathrm{ml}$ of either the sperm sonicate, isozyme I or 5 . The lactate dehydrogenase activities of the injected isozymes were generally greater than 500 international units. After an initial injection, subsequent ones were made after $1,2,5$, and 6 weeks. At the 6 th $_{1}$ week, o.I-ml injections were also made into each hind foot pad. One week later the rabbits were bled. In addition to the antisera thus obtained, antisera to heart and liver lactate dehydrogenase, which had been prepared by Nisserbaum AND BodanSKY ${ }^{10}$, were also used.

The lactate dehydrogenase isozymes were investigated by the immunochemical procedure of NisSElbaUm AND BODANSKY ${ }^{10}$. This method involves the determination of the inhibition of the activity of a lactate dehydrogenase isozyme, after incubating with antiserum and centrifuging off the precipitate. It was modified by reducing the incubation times (from 3 to $2 \mathrm{~h}$ at $37^{\circ}$ and from 68 to $\mathrm{I} 8 \mathrm{~h}$ at $5^{\circ}$ ) in order to minimize the loss of enzyme activity. The results obtained with our antisera are presented in Fig. I, while those obtained with the antisera of Nisselbaum AND Bodansky are shown in Fig. 2.

The difference in reactivity of the lactate dehydrogenase fractions with homologous and heterologous antisera demonstrates that the X-band is structurally different from isozymes I and 5. The lack of any reaction of the X-band with the heterologous antisera we prepared, over the concentration range studied (Fig. $\mathrm{x}$ ), also indicates that the $\mathrm{X}$-band is not a tetramer composed only of a combination of normal $\mathrm{A}$ and $\mathrm{B}$ subunits. If it were such a tetramer, the concentration of the A or B subunits would fall within the range in which there would be a reaction with the antiserum to isozyme $I$ or 5 .

Biochim. Biophys. Acta, I39 (1967) 507-510 


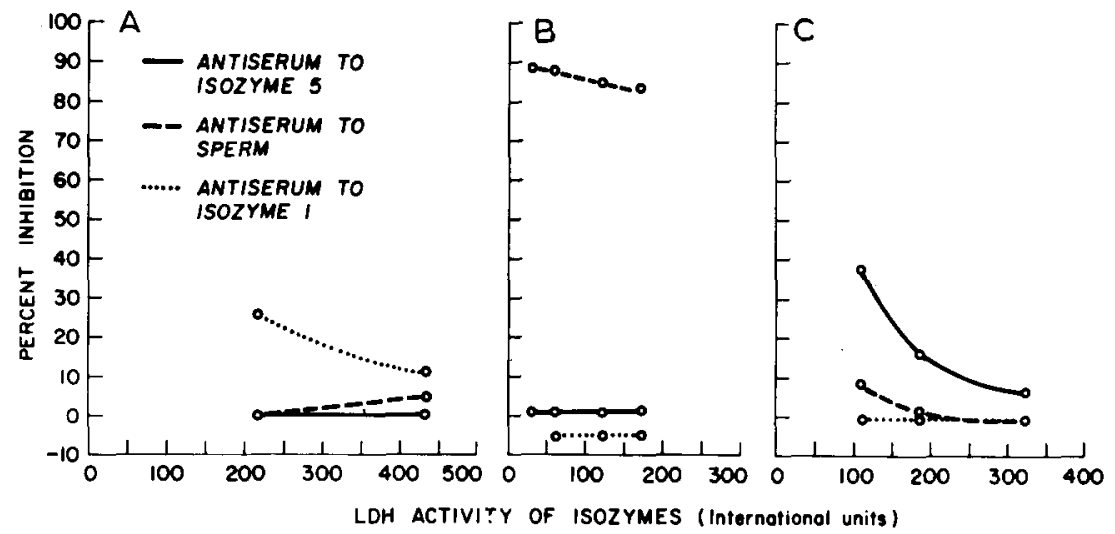

Fig. I. Inhibition of isozymes by homologous and heterologous antisera. The antisera were prepared as described in the text. The inhibition of isozyme $I$ is shown in A, that of the X-band is shown in $\mathrm{B}$, and that of isozyme 5 in $\mathrm{C}$. $\mathrm{LDH}=$ lactate dehydrogenase.

The apparent cross reaction of the $\mathrm{X}$-band with the antiserum to isozyme $\mathrm{I}$ of NisselbaUm AND BoDANSKy, even though less than that of isozyme 5, nevertheless indicates that the $\mathrm{X}$-band does have some structural characteristics in common with those of the other isozymes. This is also indicated by the hybridization and activity studies which have been cited.

The mobility of the $\mathrm{X}$-band in starch gels remains constant, relative to the other isozymes, when the starch gel concentration is varied?. Thus the molecular size of the X-band appears to be similar to the size of the other isozymes ${ }^{14}$. This finding does not support the possibility that the present results are due to an X-band consisting of normal lactate dehydrogenase subunits conjugated with another substance of large molecular size, or to conformational changes of normal lactate dehydrogenase subunits involving dissociation or aggregation reactions. The possibility of conjuga-

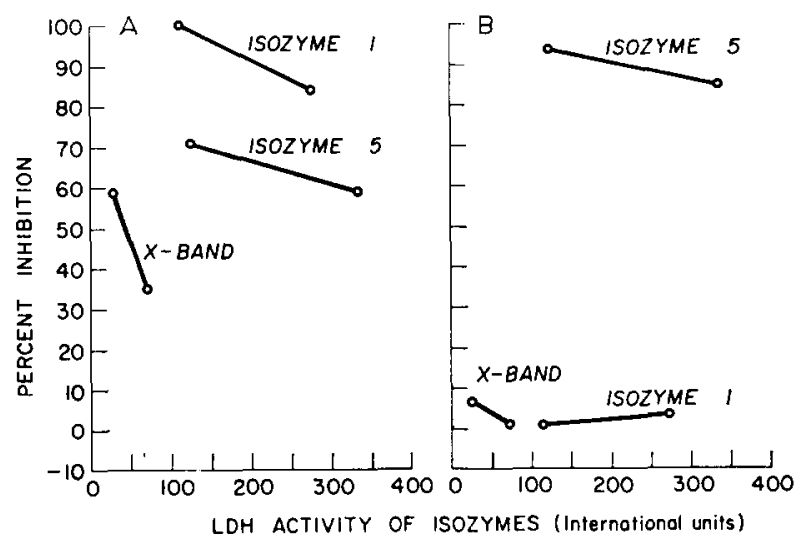

Fig. 2. Inhibition of isozymes by the antisera of Nisselbaum AND Bodansky. A, reactions with rooster antiserum to heart-type lactate dehydrogenase; $B$, reactions with rabbit antiserum to liver-type lactate dehydrogenase. The individual isozymes are designated in each case. 
tion with nucleic acids was studied in particular by attempts to absorb the antiserum with denatured RNA or DNA. No effect was observed upon the inhibition of lactate dehydrogenase activity by the antiserum.

The results of the present immunochemical analyses are consistent with the hypothesis that the $\mathrm{X}$-band is composed of subunits with a unique primary structure. The synthesis of these subunits presumably would be controlled by a third genetic locus.

The authors thank J. S. Nisselbaum and O. Bodansky for samples of their antisera. This work was supported by a grant from the U.S. Public Health Service.

Departments of Pathology and Biological Chemistry,

N. RESSLER

The University of Michigan, Ann Arbor, Mich. (U.S.A.)

K. L. STITZER

Center for Research in Reproductive Biology,

D. R. ACKERMAN

Department of Obstetrics and Gynecology,

The Univeristy of Michigan,

Ann Arbor, Mich. (U.S.A.)

i W. H. Zinkham, A. Blanco and L. J. Clowrey, Jr., Ann. N.Y. Acad. Sci., I2 I (1964) 57 I.

2 E. Goldberg, Ann. N.Y. Acad. Sci., I2I (1964) 560.

3 J. Clausen and B. Ovlisen, Biochem. J., 97 (I965) 5 I 3.

4 W. H. Zinkham, A. Blanco and L. Kupchyk, Science, I 42 (1963) I 303.

5 A. Blanco, W. H. Zinkham and L. Kupchyk, $J$. Exptl. Zool., I 56 (1964) I 37.

6 A. Blanco and W. H. Zinkham, Science, 139 (1963) 601.

7 N. Ressler, E. Olivero and R. R. Joseph, Nature, 206 (1965) 829.

8 B. G. Carter, B. Cinader and C. A. Ross, Amn. N.Y. Acad. Sci., 94 (ig6i) 3.

9 R. D. Cahn, N. O. Kaplan, L. Levine and E. Zwilling, Science, i 36 (I962) 962.

io J. S. Nisselbaum and O. Bodansky, J. Biol. Chem., 236 (Ig6r) 40 i.

i R. D. Capps, J. G. Batsakis, R. O. Briere and R. R. Calam, Clin. Chem., i2 (ig66) 406.

12 N. Ressler and R. R. Joseph, Clin. Chem., io (1964) 346.

13 P. G. Plagemann, K. F. Gregory and F. J. Wroblewski, J. Biol. Chem., 235 (1960) 2288.

I4 O. Smithies, Arch. Biochem. Biophys., Suppl. i (1962) I25.

Received February 27 th, 1967

Biochim. Biophys. Acta, 139 (1967) 507-510 